\title{
Plano de Estudo (PE) da Pedagogia da Alternância: perspectiva problematizadora na ação formativa da Escola Família Agrícola dos Cocais/PI (EFA Cocais/PI)
}

\author{
Maria Raquel Barros Lima ${ }^{1}$, Carmen Lúcia de Oliveira Cabral ${ }^{2}$ \\ ${ }^{1}$ Universidade Federal do Maranhão - UFMA. Coordenação de Ciências Humanas. Campus Codó. Avenida José Anselmo, \\ 2008, São Benedito. Codó - MA. Brasil. ${ }^{2}$ Universidade Federal do Piauí - UFPI. \\ Autor para correspondência/Author for correspondence: raquelgandhi@yahoo.com.br
}

\begin{abstract}
RESUMO. O presente trabalho objetiva a análise do Plano de Estudo (PE) da Pedagogia da Alternância em sua dimensão problematizadora na ação formativa da Escola Família Agrícola dos Cocais/PI (EFA Cocais/PI). Como indagação fundamentadora do presente estudo, questiona-se: em que medida a dimensão problematizadora mediada pelo $\mathrm{PE}$ se efetiva na EFA Cocais/PI? Essa questão se baseia na condição inerente do PE como mediação pedagógica da Pedagogia da Alternância, que é a problematização. Conectada às outras mediações, não menos relevantes, o PE articula, além dos tempos e espaços formativos, os saberes cotidianos das famílias nos processos de ensino aprendizagem. Esses elementos incorrem no desenho de uma formação veiculada à dimensão problematizadora, tendo em vista que a realidade vivenciada no cotidiano das famílias se insere no ambiente escolar através do PE. A análise dos dados apresentou a efetivação da condição problematizadora inerente ao $\mathrm{PE}$ na ação formativa desenvolvida na EFA Cocais/PI, contudo desvelou também a existência de lacunas na realização do que denominamos de ciclo do PE.
\end{abstract}

Palavras-chave: Plano de Estudo, Pedagogia da Alternância, Dimensão problematizadora. 


\title{
Alternance Pedagogy study plan (SP): Problematizing perspective on the formative action of the Cocais/PI Agricultural Family School (EFA Cocais/PI)
}

\begin{abstract}
The present study aims to analyze the Study Plan (SP) of the Alternation Pedagogy in its problematic dimension in the formative action of the Cocais/PI Agricultural Family School (EFA Cocais/PI). As a grounding question of the present study, the question is: to what extent is the problematizing dimension mediated by the SP effective in the EFA Cocais/PI? This question is based on the inherent condition of the SP as the pedagogical mediation of the Alternation Pedagogy, which is the problematization. Connected to other mediations, no less relevant, the SP articulates, beyond the formative times and spaces, the daily knowledge of families in the processes of teaching and learning. These elements incur the design of a formation conveyed to the problematizing dimension, considering that the reality experienced in the daily lives of families is inserted in the school environment through the SP. The data analysis showed the effectiveness of the problematic condition inherent to the SP in the formative action developed in the EFA Cocais/PI, but also revealed the existence of gaps in the realization named the SP cycle.
\end{abstract}

Keywords: Study Plan, Pedagogy of Alternation, Problematic Dimension. 


\section{Plan de Estudio (PE) de la Pedagogía de Alternancia: Perspectiva problematizadora en la acción formativa de la Escuela Familia Agrícola de los Cocais/PI (EFA Cocais/PI)}

RESUMEN. El presente trabajo objetiva el estudio del Plano de Estudio (PE) de la Pedagogía de la Alternancia en su dimensión problemtizadora en la acción formativa de la Escuela Familia Agrícola de los Cocais/PI (EFA Cocais/PI). Como indagación fundamentadora del presente estudio, cuestiona-se: En qué medida la dimensión problematizadora mediada por el PE se efectiva en EFA Cocales/PI? Esa cuestión se basa en la condición esencial del PE como mediación pedagógica de la Pedagogía de la Alternancia, que es la problematización. Conectada a otras mediaciones pedagógicas de la alternancia, no menos relevantes, el PE articula, además de los tiempos y espacios formativos, los saberes cotidianos de las familias a los procesos de enseñanza y aprendizaje. Esos elementos generan en el dibujo de una formación que se encuentra entrelazada a dimensión problematizadora, gritando atención para el facto que la realidad del cotidiano de las familias se encuentran presente en ambiente escolar a través del PE. El análisis de los dados presentó la efectivación de la condición problematizadora según la naturaleza del PE. En La acción formativa en EFA Cocais/PI, sin embargo, el estudio desveló también la existencia de rasgos en la realización del que nombramos ciclo del PE.

Palabras clave: Plan de Estudio, Pedagogía de la Alternancia, Dimensión Problematizadora. 


\section{Introdução}

A perspectiva problematizadora do Plano de Estudo (PE) atribui a essa mediação a qualidade de articuladora dos tempos, espaços e saberes na formação em alternância. A ação educativa que se realiza em conformidade com o PE incide no respeito à inserção dos saberes culturais das famílias participantes nesse processo. $\mathrm{O}$ PE, compondo as Mediações Pedagógicas da alternância, efetiva, a partir da realidade social, política, econômica e cultural das famílias dos educandos o caráter problematizador na formação desses jovens.

Estas Mediações Pedagógicas da Pedagogia da Alternância marcam a diferenciação nos processos de formação da juventude camponesa, em relação com outras escolas que se localizam no campo. Primeiramente, por que essa modalidade é própria das Escolas Famílias Agrícola (EFAs), as quais se situam preferencialmente no campo. Outro ponto repousa no fato do aspecto problematizador da realidade cotidiana das famílias que se encontram inseridas nas EFAs.

A dimensão problematizadora fomentada pelo PE, visto ser essa mediação responsável pela sistematização de questões investigativas da realidade das famílias e comunidade, potencializa processos formativos que visam o protagonismo dos jovens como potenciais sujeitos transformadores de sua realidade.

Notadamente instigante, o PE em sua consistência pedagógica encontra-se imbricado em uma rede de relações instrumentais com outras mediações, cuja articulação termina por conduzir a ação educativa na modalidade da alternância de forma significativa e contextualizada. É certo que as 17 EFAs, que atualmente funcionam no estado do Piauí, possuem caráter diverso devido à localização em regiões distintas no Estado. Este aspecto proporciona riqueza de vivências relativas à materialização dessas mediações, entre essas, a dinamização do PE. Assim, delimitamos este estudo ao contexto da Escola Família Agrícola dos Cocais - EFA Cocais/PI, a fim de estudar o caso específico relativo à efetivação do PE.

A EFA Cocais está situada no município de São João do Arraial, especificamente na localidade Quente, que se encontra localizada a $3 \mathrm{~km}$ da sede municipal, no estado do Piauí. As famílias circunvizinhas da EFA são agricultoras, o que constitui uma localidade voltada para produção na agropecuária objetivando o sustento familiar. Os cursos técnicoprofissionalizantes ofertados pela EFA são: Técnico em Agropecuária, Agroindústria e 

ação formativa da Escola Família Agrícola dos Cocais/PI (EFA Cocais/PI)...

Administração Rural. Esse último, atualmente, mesmo com a oferta do curso não há demanda. Professores e os demais profissionais são contratados através de teste seletivo realizado pela Secretaria de Educação do Estado - SEDUC. Vale ressaltar que as EFAs encontram-se na condição de estadualizada, sendo assegurada às mesmas a escolha do gestor e relativa autonomia administrativa.

A delimitação da EFA Cocais neste estudo se justifica pela experiência da pesquisadora como educadora dessa Instituição, em 2013, o que facilitou o acesso e permanência da pesquisadora no campo de pesquisa, tendo em vista se tratar de um relato de estudo de caso caráter etnográfico. Outro argumento repousa no fato da escola possuir associação de pais relativamente atuante. Este aspecto da existência da associação configura-se como dimensão característica à Pedagogia da Alternância em sua proposta de ação educativa.

Essa experiência como educadora na EFA, com a participação nos momentos da trajetória de preparação, motivação, realização no tempo/espaço familiar e socialização no retorno dos estudantes à sessão escolar do PE na EFA Cocais, motivou a indagação problema para este estudo: em que perspectiva o PE articula a dimensão problematizadora nos processos formativos na EFA Cocais/PI? Indagação que se estende às outras mediações de forma indireta, visto que: a colocação em comum, tutoria, caderno da realidade, caderno de acompanhamento, visita à família e comunidade, visitas e viagens de estudo, serões, intervenções externas, atividades de retorno, Projeto Profissional do Jovem, encontram-se imbricadas ao PE em sua ação articuladora formativa nas EFAs.

Cada uma dessas mediações pedagógicas dinamiza uma circunstância formativa sem, contudo desvincular-se do aspecto abrangente intrínseco aos processos formativos em alternância. Além da articulação entre essas mediações existe a dimensão interdisciplinar que as mesmas fomentam no tempo/espaço escolar.

A pesquisa enveredou pelo estudo de caso de caráter etnográfico em educação, na perspectiva de André (1995, 1984). A autora traz uma contribuição para pesquisa em educação pelo o viés da etnografia de forma a flexibilizar a estadia no campo de pesquisa sem prejuízos dos resultados. As técnicas utilizadas para produção de dados foram: a entrevista narrativa e a observação participante que, conforme Angrosino (2009), significa a inserção no contexto onde ocorre o fenômeno, durante a qual foi produzido o diário de campo. Para análises dos dados usamos as 
perspectivas da Análise do Discurso (AD), na concepção de Bakhtin (2006) através da leitura de Brait (2005) e a Análise do Discurso Crítica (ADC) de Fairclough (2008).

A inserção no campo empírico aconteceu durante o ano de 2018 e seguiu a dinâmica da sessão escolar da turma do terceiro ano do curso de Agropecuária. Participaram na investigação: 02 professores, 02 professores responsáveis pela gestão da escola, 02 membros da associação de pais e 03 estudantes do terceiro ano de Agropecuária. A fim de preservar a identidade dos participantes no estudo, foi acordado identificá-los pelos pseudônimos dos planetas do sistema solar, sob a justificativa da dinâmica sistêmica que existe entre estes corpos celestes e o sol, gerando um movimento contínuo.

Este relato de estudo estrutura-se em três seções, além da introdução e considerações finais. A primeira seção preocupa-se em fundamentar a perspectiva teórica das análises, visto a complexidade que assinalam; a segunda se detém sobre o Plano de Formação, instrumental de suporte do Plano de Estudo na EFA Cocais; na terceira seção o foco se volta para a dimensão problematizadora do PE na perspectiva dos participantes da pesquisa que efetivam a ação formativa na EFA.

\section{Sustentação teórica das análises}

Nesta seção articulam-se as duas perspectivas de análise discursiva, compreendendo que a articulação se torna necessária a fim de conferir o suporte teórico que atribui ao trabalho rigor $\mathrm{e}$ responsabilidade com relação aos dados produzidos, principalmente ao se tratar da prática de análise da fala dos participantes.

Brait (2005, p. 88), ao afirmar que, em se tratando da base conceitual de linguagem, essa se encontra comprometida com “... uma visão de mundo que, justamente na busca das formas de construção e instauração de sentidos...", expressa as variadas maneiras de compreensão da realidade e do mundo. A autora reverbera e discute os tratados de Bakhtin (2006) acerca da interação verbal. Neste sentido, o foco está voltado para a primazia na produção de sentidos, sustentando que Bakhtin concebe o significado como dimensão limitada em comparação com a produção do sentido.

Articulado em Bakhtin, Fairclough (2008) coloca que a linguagem está associada ao caráter ativo e à intervenção no mundo. Pontua também que a linguagem é uma prática social, o que nega a possibilidade de construção discursiva de forma individual e isolada da dimensão sócio cultural dos sujeitos. Esta postura do autor se articula diretamente com os 
pressupostos de Bakhtin (2006), quando esse afirma que a construção discursiva se encontra imbricada no princípio básico de sua construção teórica conceitual, a alteridade, fundamento das relações interativas sociais constitutivas do discurso.

O foco no discurso na perspectiva teórica da ADC como forma de estabelecer a compreensão sobre o caráter problematizador do PE em sua constituição na EFA Cocais, ajuda a trabalhar aspectos que se apresentam ou se encontram veladas na fala, postura e prática dos sujeitos que dinamizam o PE na EFA Cocais no cotidiano. Enveredar pela AD e ADC como perspectiva de análise dos dados produzidos no campo de pesquisa, proporcionou a oportunidade de compreender a produção de sentidos que acontece em torno do PE em sua dimensão problematizadora, entre os sujeitos que o efetivam nos tempos/espaços da formação.

\section{Plano de Formação da EFA Cocais: base constitutiva do Plano de Estudo}

O Plano de Formação se constitui no meio pelo qual a ação educativa a EFA Cocais assume as temáticas que refletem a realidade das famílias articuladas aos conteúdos e saberes do cotidiano. Faculta e propicia uma educação cujo viés problematizador do PE torna-se crucial aos processos formativos em alternância. Antes de enveredar pela perspectiva problematizadora do $\mathrm{PE}$, vale ressaltar que essa mediação pedagógica, segundo Jesus (2011, p. 81), “... integra a vida, o trabalho, a família com a EFA", condição que coloca o PE como principal mediação pedagógica, o que possibilita observar a vivencia e os discursos dos sujeitos que efetivam o trabalho educativo na EFA Cocais.

A investigação apresentou através dos discursos dos participantes na pesquisa, bem como da observação participante, a existência de um ciclo organizacional, dinâmico, processual e contínuo do PE. A denominação de ciclo foi arquitetada por entender que o PE se faz numa construção dinâmica contínua, sendo essa mediação carregada de intencionalidade problematizadora. As temáticas problematizadoras que se encontram no PE constituem o Plano de Formação, apresentado pelo diretor no início do ano letivo no encontro pedagógico para os profissionais da EFA e para representações das famílias e estudantes, que se caracterizam como projeto de formação segundo a Pedagogia da Alternância.

A construção do Plano de Formação na EFA Cocais obedece a existência de um momento inicial que se desenha de modo 
centralizado na figura do diretor. Este é um dado interessante, pois $\mathrm{o}$ diretor sistematiza esse documento individualmente e apresenta para apreciação de seus pares. Essa prática compromete a elaboração do PE, visto ser sua natureza participativa e articuladora entre saberes popular e científico. A observação participante evidenciou que a primeira etapa de constituição do $\mathrm{PE}$, a construção do Plano de Formação, desvincula-se da prática de participação de todos, famílias, professores, estudantes, da construção do documento que é concebido como eixo central na formação em alternância.

Esta postura presente na EFA Cocais encaminha para a percepção de possíveis manifestações de um poder centralizado no diretor, em nome da implementação ideológica sobre os direcionamentos que a escola precisa observar em sua ação educativa, presente no Plano de Formação. Reitera-se que é através do Plano de Formação, sistematizado na semana pedagógica da EFA no início do ano letivo, que são apresentados os temas geradores, que fundamentam as temáticas do $\mathrm{PE}$, esses articulados à realidade das famílias dos jovens.

Acerca do Plano de Formação, Gimonet (2007) afirma ser um instrumento marcador de ação educativa significativa e contextualizada dos processos formativos dos jovens. Todavia, este documento ainda representa constante desafio para todos da EFA Cocais, convocados para realizar a articulação entre aquilo que a alternância prima, problemáticas da realidade cotidiana das famílias vinculadas aos conteúdos formais, com vistas a provocar transformação da realidade camponesa através do protagonismo dos jovens estudantes.

Um dos desafios repousa no fato das dificuldades de envolvimento de todos os profissionais, bem como das famílias com a desenvoltura do que se encontra sistematizado no Plano de Formação. O Plano de Formação na EFA Cocais - 2018, cujo objetivo geral é: Elaborar e implementar o Projeto Profissional do Jovem, buscando o desenvolvimento local, qualidade de vida, sustentabilidade e renda (Plano de Formação da EFA Cocais/PI, 2018), está sistematizado em:

I - Tema Gerador - eu, a família e a terra.

II - Temas do Plano de Estudo:

- Alternativas de sobrevivência no campo e Projeto Profissional do Jovem - PPJ.

- Economia Solitária.

- Políticas Públicas.

- Movimentos sociais e sindicais.

- A EFA na minha vida. 
Para cada tema gerador do PE, existe um enfoque motivacional elencado de acordo com a sequência desses temas geradores a serem trabalhados em cada sessão, em conformidade com a sistematização presente no Projeto Político Pedagógico da EFA Cocais/PI, assim disposto:

- Questões - sociopolíticas e econômicas; A importância do PPJ para o Projeto de vida (para onde quero ir?). Este enfoque existe para potencializar o que a EFA define como empreendedorismo dos jovens técnicos, motivando o desenvolvimento local de forma agroecológica, segundo as orientações formativas da EFA Cocais.

- "Conhece-te profissionalmente" Sou profissional - e agora? Os jovens são preparados para as adversidades da profissão de técnico agrícola. A EFA Cocais direciona para formação técnica voltada para os princípios da agricultura familiar. $\mathrm{O}$ grande desafio é os jovens técnicos se afirmarem neste sentido, tendo em vista a demanda de trabalho ofertada pelo agronegócio. Criar identidade profissional técnica firmada pelos princípios da agricultura familiar é o foco de discussão neste ponto.

- Memorial do trabalho solidário;

Contexto histórico do associativismo e cooperativismo. Para EFA Cocais uma das maiores preocupações é o envolvimento dos jovens técnicos agrícolas com ações produtivas voltadas para o associativismo e cooperativismo.
- Financiamento de projetos;

Viabilidade econômica da produção; ATER - controle;

Participação popular social

Crédito agrícola: onde e como

buscar, como utilizar;

Políticas públicas para o campo.

Os Projetos Profissionais dos

Jovens (PPJ) são preparados para captar recursos a fim de materializar-se. $\mathrm{O}$ enfoque para esses elementos preparam os jovens técnicos para pleitear, além das políticas voltadas para produtividade no campo, capital para investimento a fim de realizar PPJ.

- Histórico: Caracterização e diferenciação - Campo de atuação (onde e como estão organizados em cada município). Relevante para atuação técnica profissional dos jovens é o conhecimento das potencialidades regionais e suas particularidades.

- O que esse tempo da EFA mudou em minha vida: individual, família e comunidade;

Sou egresso: e agora? Compromisso da EFA Cocais com os egressos. Aqui o enfoque para o comprometimento da EFA com a desenvoltura sócio profissional dos jovens técnicos agrícolas.

Dando continuidade, em sua sistematização o Plano de Formação coloca Serões e atividade retorno como espaços de aprofundamento das temáticas pontuadas anteriormente. Esta última com foco para definição do tema do Projeto Profissional do Jovem. Como tópico de conclusão, o documento apresenta as 
"habilidades e competências que assinala sobre Identificação das potencialidades e da propriedade, viabilidades (infraestrutura, localização, natureza); Levantar os desafios de diversas origens, discutindo possíveis alternativas de permanência no campo." (Plano de Formação da EFA Cocais/PI, 2018).

$\mathrm{O}$ último ano do curso enfatiza o pilar do desenvolvimento local e o empreendedorismo, preparando de fato os jovens para desenvolverem atividades na economia local, respeitando as potencialidades regionais. A partir do objetivo geral, o foco é a implementação do PPJ como oportunidade de geração de renda para os técnicos e suas famílias, bem como potencializar o desenvolvimento da região voltado para atividade produtiva. A ação formativa na EFA Cocais se pauta pela dimensão agroecológica de desenvolvimento produtivo. Neste sentido, a escola possui parceria do núcleo formativo da Universidade Federal do Piauí - UFPI, no pólo de Parnaíba, que facilita formação nesta linha para alguns jovens matriculados na escola.

O viés para o trabalho produtivo na escola direcionado para a agroecologia é voltado para aspectos que rompem com uma visão mais capitalista própria do agronegócio. De acordo como escrito nos documentos da escola - o Plano de
Formação e o Projeto Político Pedagógico - PPP, os PEs são condicionantes de uma perspectiva mais voltada para o exercício do modelo agroecológico de produção na propriedade dentro dos parâmetros da sustentabilidade, do respeito às relações solidárias no campo da economia.

Para situar o PE em sua relevância para o trabalho formativo na EFA Cocais, é preciso que haja a compreensão do Plano de Formação como documento vital e imperioso na dinâmica de realização da formação na EFA. Isso por conter o cerne do que orienta os processos formativos, sendo no Plano de Formação que estão contidas as diretrizes para a dimensão problematizadora do $\mathrm{PE}$, bem como a realização das outras mediações que, ao se articularem, propiciam um planejamento orgânico e interdisciplinar, materializado como proposta de ação educativa na EFA Cocais. Com a observação participante foi possível perceber um quadro contraditório de efetivação das diretrizes pontuadas no Plano de Formação, a partir da formatação do documento realizada de forma individualizada e posta para aprovação.

Acerca dessa constatação, as contribuições de Gimonet (2007, p. 69) ao afirmar que este instrumental é “... orquestração de conjuntos ...”, ajuda no questionamento da forma com que a construção desse instrumental ocorre na 
EFA Cocais, pois na concepção de que fala o autor, é crucial o envolvimento de todos os sujeitos imbricados aos processos formativos na EFA.

Este questionamento se funda em um dos princípios fundamentais do movimento das EFAs, que é a participação coletiva nos direcionamentos das escolas. Este ponto tornar-se cabível de reflexão, principalmente ao se tomar como suporte o que Mészáros (2005) coloca sobre as manobras de ajustes que ocorrem na sociedade capitalista no que diz respeito à educação. Sendo assim, tal proposta de formação, no caso a alternância incorre no risco da perspectiva do ajuste, terminando por encaminhar-se na contra mão da ação educativa proposta pela Pedagogia da Alternância, como apregoa o discurso das EFAs no Estado. Acerca da trajetória de construção do Plano de Formação da EFA Cocais, Mercúrio coloca na

... semana pedagógica... eh, eu fiz [foi feito] um estudo...um levantamento de plano de estudo de várias escolas, [entrando] em contato com várias escolas, tenho[tendo] experiência com outras escolas, já tinha esse plano...fui...vi...eu li acho que[encontrou] duas dissertações que falavam sobre plano de formação e temas do plano de formação, verifiquei[verificando] possíveis temas dentro da região mesmo que a gente já trabalhava, vi[viu] o que já deu certo e o que não deu certo nesses anos todos.Então,listei[listou] todos esses temas, com enfoques também...eh...e relacionei[relacionou] isso de acordo com o tema gerador do primeiro ano, do segundo e do terceiro ano. (Mercúrio/Entrevista).

$\mathrm{Na}$ fala de Mercúrio detecta-se contrapontos importantes, a começar pela dinamicidade de construção do Plano de Formação que deveria acontecer em conformidade com o que o movimento dos Centros Familiares de Formação por Alternância - CEFFAs pontuam sobre a participação das famílias de forma a fortalecer o protagonismo das mesmas. A trajetória de constituição desse documento obedece a um percurso no qual o diretor está como dinamizador e condutor de todo o processo, conforme se desvela na fala de Mercúrio.

A trajetória de construção termina na apresentação do produto aos outros sujeitos que compõem a comunidade escolar, professores e alguns representantes da associação das famílias. É considerável demarcar que a participação das famílias se dá em momentos pontuais, o que leva a perceber que existe uma lacuna nessa efetiva intervenção das famílias na gestão compartilhada.

A centralidade dos momentos preparatórios prévios para constituição do documento na pessoa do diretor pode incorrer no risco de distanciamento dos demais sujeitos que são partes relevantes ao processo, segundo o que condiz com o princípio fundamental do movimento das 
EFAs, a participação efetiva das famílias de forma significativa. A participação desses sujeitos é assegurada, na perspectiva de Gimonet (2007), ao pontuar acerca da colaboração que deve acontecer na constituição desse documento. Segundo o que alega o autor, esse momento é “... um trabalho de cooperação entre representantes dos vários parceiros da formação e dos administradores da associação". (Gimonet, 2007, p. 72). O autor como um dos expoentes do CEFFAs chama atenção para o aspecto da coletividade, sob tudo dos coformadores como co-responsáveis na ação formativa.

A fala de Mercúrio denuncia uma acentuada postura verticalizada das relações que, em alguns momentos se mesclam a exercícios de poucas ações horizontais, como, por exemplo, e como já citado, a participação de todos em selecionar ou aprovar as temáticas que compõem o Plano de Formação e que servem de eixos temáticos para constituição do PE em 2018. Verifica-se que o grau de exercício participativo se restringe a estes momentos.

Neste sentido, configurar exercício da gestão democrática como uma prática rotineira na EFA Cocais, é responsabilidade de todos os envolvidos, sendo preciso que todos que dinamizam a formação em alternância se mantenham em constante autoavaliação de suas funções, bem como do envolvimento de cada um e de forma coletiva para contribuição na gestão participativa e na efetivação dinâmica do Plano de Formação no cotidiano do trabalho educativo, em concordância com Gimonet (2007, p. 69) sobre “... orquestração em conjunto...".

No que diz respeito aos contratempos no cotidiano da escola externados sobre a não observância do Plano de Formação como diretriz formativa na EFA Cocais, a fala de Marte (entrevista), participante da pesquisa, coloca que na semana pedagógica são escolhidos os “... temas a serem trabalhados... vai vendo os conteúdos que tem que ser, pra ir encaixando... da base comum ..., que a base técnica já é uma obrigação, tem que tá lá ...”. (Marte/entrevista).

A fala desse sujeito evidencia a preocupação em seguir uma diretriz estabelecida pelo Plano de Formação em alternância, no que se percebe a intenção controladora que se desenha em torno deste documento no contexto escolar. A compreensão da existência de grupos que se posicionam de forma distinta na EFA Cocais, com relação à observância do Plano de Formação e sua diretriz para efetivação do trabalho educativo, demonstram a luta contra hegemônica que se desenha neste espaço, conforme 
Fairclough (2008) alerta. Percebe-se a intensidade dessa luta no cotidiano, principalmente entre os professores e a gestão da escola. Inclusive, pode-se pontuar como uma das possibilidades de análise da fala de Marte sobre a questão interdisciplinar, que existe uma prática de resistência da maioria dos professores sobre a modalidade da alternância, cujas implicações estão voltadas para dinamização das mediações pedagógicas e interdisciplinaridade como processo norteador formativo.

No tocante ao princípio da interdisciplinaridade do Plano de Formação e por extensão, as mediações pedagógicas, entre estas o PE, Marte ainda pontua que infelizmente a realização interdisciplinar que esse documento encaminha encontra-se centralizada no trabalho educativo de uma disciplina especificamente, no caso Geografia. Vale enfatizar que os participantes na pesquisa situaram a disciplina de Geografia como a única que procura articular os conteúdos da disciplina com as temáticas abordadas no PE, quando é possível fazer essa articulação interdisciplinar.

Em sua fala, Marte afirma que quase não há a articulação dos conteúdos da base comum com os temas do PE, que se encontram sistematizados no Plano de Formação. Ao colocar sobre a articulação entre as disciplinas, pontua que são “... pouquíssimas vezes... logo é muito complicado encaixar conteúdos de sala de aula com o PE, porque vem aquela coisa tão formal..., o PE é muito dinâmico... o que se dá mais de ser... o que [já presenciou] foi a questão da Geografia.". Nas palavras de Marte a relação conflituosa entre o programa oficial e o Plano de Formação, evidencia o entrave para dinamização expressiva do PE. Encontra-se, na fala de Marte dificuldades de se perceber os limites do programa oficial e a desenvoltura do Plano de Formação como documento primordial da ação educativa na EFA Cocais.

A disciplina de Geografia consegue em alguns momentos, segundo Marte, estabelecer vinculo interdiciplinar entre o que os conteúdos próprios dessa disciplina expõem com o que o PE problematiza. Para Marte, esse fato se dá, principalmente, com a turma do terceiro ano de Agropecuária, devido às temáticas dos PEs no Plano de Formação encontrar-se voltadas para questão produtivas, foco de ensino-aprendizagem no último ano do Curso. O modo como a disciplina é orientada consegue conduzir ações formativas que se articulam aos PEs. Essa é uma atitude que leva os estudantes inclusive a questionarem e mesmo reclamarem, segundo a fala de Marte: “... é 
só a [Geografia] que vai pro PE?! ...”. (Marte/entrevista).

Outro aspecto não menos importante é a ocorrência no ambiente escolar da presença dos grupos organizados de professores que divergem politicamente no que diz respeito a partidos políticos, que terminam por causar momentos de intensa investida junto aos estudantes, no momento da aula, sobre as investiduras na conquista de votos. Visto como uma situação que pode desvelar a ausência do aspecto problematizador relacionado à função da escola como espaço de autonomia para discussão e questionamentos acerca de projetos políticos que se apresentam para implementação no País, Estado e Município.

Com essa configuração da prática, é possível que as temáticas sobre a realidade pontuada no Plano de Formação acerca da diretriz para construção do $\mathrm{PE}$, fiquem engessadas e não desenvolvam efetivamente a dimensão problematizadora de forma ampliada a todas as questões políticas, sociais, culturais e econômicas que essa mediação sinaliza. $O$ contexto político partidário no período especificamente das eleições assinala no interior da escola um campo de disputa de grupos contrários que almejam a hegemonia de seus projetos políticos.
Salienta-se que, esse seria um momento fértil de problematização entre os jovens educandos acerca da ideologia e hegemonia dos projetos políticos que se encontram em constantes disputas.

Com relação ao aspecto da discussão voltada para questões políticas, os embates ideológicos acontecem em algumas ocasiões de forma sinuosa no interior da instituição, em outras ocasiões bem mais externadas. No dia a dia da escola, os estudantes denunciam nos espaços de encontros informais, ou seja, fora do ambiente da sala de aula, os assédios que sofrem dentro da sala de aula com relação à apresentação de projetos políticos partidários em disputa eleitoral.

Mesmo com esses impasses, na sua maioria velada e até em alguns momentos ignorados, nota-se a busca pela convivência, relativamente harmoniosa no ambiente escolar, cujas inter-relações demonstram uma aparente parceria entre professores e gestão no que diz respeito à ação formativa na EFA Cocais. Gimonet (2007) ressalta a relevância do sujeito em sua história, sendo protagonista.

O fato é que as relações vivenciadas no convívio dos sujeitos no ambiente escolar estimulam as variadas temáticas que poderiam ser problematizadas através do PE, entre as quais a interdisciplinaridade por ser dimensão que 
dar consciência ao Plano de Formação, enquanto documento norteador dos processos formativos em alternância no movimento CEFFAs, o que justifica enfatizar a realidade desvelada na observação participante.

Entre as situações vivenciadas, percebeu-se a supremacia do livro didático como aspecto que alimenta as desculpas por parte da maioria dos professores em não conseguir articular os conteúdos da base comum com as temáticas que se encontram no Plano de Formação e sustentam a realização do PE. Existem reclamações, sobretudo da gestão, para que os professores realizem a interdisciplinaridade, articulando em suas aulas as discussões problematizadas pelo PE e Colocação em Comum, outra mediação pedagógica da Pedagogia da Alternância, e os conteúdos do livro didático. Todavia, não se constatou ocorrência de um momento de formação e sensibilização com os professores de forma objetiva sobre as alternativas e formas de trabalhar a interdisciplinaridade, o que remete à possibilidade dos professores não saberem como agir.

\section{Plano de Estudo: mediação pedagógica de natureza problematizadora}

A dimensão problematizadora faz parte da origem do movimento das
Maisons Familiale Rurales - MFRs, na medida em que seus expoentes teóricos reconhecem esta dimensão como um dos elementos, senão o principal, de maior relevância e responsável pela construção das primeiras experiências de formação em alternância com surgimento no contexto campesino francês a partir de 1935, conforme Gimonet (2007). A fundamentação conceitual da problematização como foco principal neste trabalho torna-se necessária, visto que a investigação se concentra na indagação sobre como o PE da Pedagogia da Alternância efetiva a articulação da dimensão problematizadora entre tempos/espaços na EFA Cocais de maneira a envolver todos os sujeitos na ação educativa.

Ao se tratar de uma formação dinamizada pelo o viés problematizador como suporte da ação educativa na EFA Cocais, o PE se constitui como a mediação pedagógica que possui as funções em articular temáticas relacionadas à realidade das famílias com o trabalho formativo desenvolvido com os estudantes. Ao tomar o PE em sua intencionalidade problematizadora, enfatiza-se a função dessa mediação como potencializadora da ação educativa, pautada pelo o exercício de problematizar através dos eixos temáticos presentes no Plano de Formação. Insiste-se 
que esses eixos temáticos são selecionados pelos sujeitos que dinamizam o trabalho educativo na EFA Cocais. Esses eixos dispõem de enfoque que, por sua vez, se colocam como temáticas fundamentadoras das questões que constituem o $\mathrm{PE}$, conferindo-lhes um caráter problematizador da realidade e impulsionador de processos emancipatórios formativos.

Tecendo uma teia de contribuições acerca do aspecto conceitual sobre a problematização, desenvolve-se, neste trabalho uma articulação entre aquilo que alguns teóricos pontuam em relação ao entendimento de problematizar, e os sentidos atribuídos pelos participantes na pesquisa, no que tange á temática em discussão. Em confirmação com essa perspectiva, percebe-se na fala de Júpiter uma demonstração da atitude problematizadora, estreitamente relacionada ao

... problema...(risos)...uma questão que envolva discussão...a problematização, ela tem que envolver a discussão, a fala, o contexto...o discutir mesmo. Então é um assunto que envolve opiniões. $\mathrm{O}$ $\mathrm{PE}$ possui $\mathrm{O}$ caráter problematizador...Porque ele traz as discussões...ele foca num assunto que envolve opiniões...que envolve e discute, que envolve a vida, o cotidiano...é....as ações de um determinado lugar e seus indivíduos. (Júpiter/entrevista).
A fala de Júpiter aproxima-se da perspectiva de Freire (1987) ao tratar da problematização como dimensão que traz uma abordagem direta do cotidiano para reflexão no contexto da ação educativa. Para Júpiter, o fato de o PE proporcionar discussões em torno dos assuntos relacionados à vida, já o coloca como uma mediação pedagógica de intencionalidade problematizadora. Entre as contribuições dos demais participantes nesse estudo, Júpiter consegue, dependendo da temática do PE, articular o resultado da socialização do PE, bem como o eixo temático do mesmo, com seus conteúdos em sala de aula.

Para Freire (1987), a educação problematizadora supera os distanciamentos entre os conteúdos e a vida dos sujeitos em formação. É uma dimensão que pressupõe a prática da dialogicidade. Trabalhar o termo dialogicidade, em Freire (1987), remete à compreensão da palavra como ação realizada na alteridade. Para o autor, a palavra dita deve confundir-se com a ação realizada. $\mathrm{O}$ entrecruzamento das opiniões e das falas dos participantes na pesquisa exerce um dos aspectos da dialogicidade a do encontro entre diálogos e, para esse encontro ser coerente com a dimensão dialógica, precisa produzir transformações, 
sejam sociais, culturais ou pessoais (Freire, 1987).

$\mathrm{Na}$ perspectiva de Vênus, a problematização está ligada a respostas e soluções que se encontram acerca das circunstâncias produtivas e que são tidas como problemas a serem solucionados. Em suas palavras, Vênus diz que a problematização

... é algo que existe em algum lugar que... como posso dizer (pensativa)... que ele não tem desenvolvimento que supre a necessidade da comunidade..., por exemplo: tem uma determinada área que os alunos fazem um tipo de plantio... Épocas dá [boa colheita]... épocas que não dá, então é... eh... é problematização! (Vênus/entrevista).

Esta perspectiva apresentada por Vênus enfatiza sua atuação com a dinamização dos PEs, no sentido de que a tônica na EFA para construção dos PEs é que o tema a ser desenvolvido deve estar vinculado à realidade da propriedade das famílias. Percebe-se que o foco para o termo problematização se constitui, nesse sentido, de potencializar soluções acerca dos processos produtivos, com enfoque para o trabalho, nas famílias. Nas colocações de Vênus existe a tendência de vincular a dimensão problematizadora das questões do $\mathrm{PE}$ ao trabalho produtivo familiar.

O PE na EFA Cocais, além das questões relativas ao trabalho produtivo no campo é uma mediação que consegue promover uma educação problematizadora, com seus temas geradores em torno de outras dimensões como as famílias e não somente na lida com a terra. Os enfoques que servem de base para construção das questões que compõem o PE, são construídos de forma a possibilitar problematizações acerca de aspectos mais gerais da realidade dos estudantes, conforme evidenciado neste estudo. Os cinco (05) PE's observados durante a pesquisa provocaram abordagens desde a relevância da forma de produção de base agroecológica, questionando o uso de incentivos químicos nocivos à vida, até a necessidade de acesso às políticas de incentivo aos jovens agricultores em seus PPJ's.

Entretanto, o estudo mostrou existir uma ruptura no que denominados ciclo contínuo do PE, que se inicia com a construção dos temas geradores que estão colocados no Plano de Formação. Desses temas geradores, surgem os enfoques que serão trabalhados, através da sensibilização temática, que são de responsabilidade dos professores. Com os estudantes, a sensibilização é um momento de apresentação do tema, utiliza-se da forma criativa, com filme, ou com explanação dialogada sob a organização do professor responsável pela mobilização do $\mathrm{PE}$ na 
EFA Cocais de acordo com calendário planejado desde o início do ano letivo.

A partir da mobilização, sensibilização do tema do PE, os estudantes são motivados a construírem as questões, que variam conforme a relevância do tema para os mesmos. A construção dessas questões passa pelo crivo dos professores responsáveis/ou professor responsável, de acordo com o rodízio entre as coordenações dos PE's.

Terra, participante da pesquisa, descreve de forma bem didática o percurso de construção do PE na EFA Cocais.

O Plano de Estudo feito aqui na EFA Cocais, ele começa com uma mobilização com os alunos, é...com todos os alunos dessa sessão $\left(3^{\circ}\right.$ ano $)$ juntos no auditório, e lá eles passam um tema...é...aquele tema é abordado de uma forma é...em forma de conversa, eles explicam pra gente como é que é ser feito, o que trata o tema e eles propõem que a gente faça umas questões para a gente tá levando para nossa casa, comunidade, cidade, para casa e para está respondendo essas questões e trazendo novamente para escola pra gente está mostrando as nossas questões, nosso ponto de vista, pesquisa e tá expondo para os professores e para nossos colegas. (Terra/entrevista).

O percurso de constituição do PE no entendimento de Terra se inicia com a mobilização dos estudantes no auditório. Este é um fato interessante, pois a prerrogativa para que o PE exista é retratar a realidade concreta dos estudantes vivenciada em seu meio sócio profissional. A fala de Terra levou a considerar que o PE para os estudantes se encontra perspectivado apenas pela construção das questões.

$\mathrm{O}$ fato de Terra enfatizar de maneira incisiva o pronome pessoal "eles", eles passam/eles explicam/eles propõem denota um controle velado dos professores com relação à trajetória e ao aspecto problematizador do PE. Esse elemento também demonstrar que para os professores o caráter problematizador do PE se deve somente à Colocação em Comum, momento de socialização das questões respondidas pelos estudantes, ou da pesquisa, conforme denomina Terra, e que costuma gerar os debates sobre a apresentação dessas questões.

Todavia, para consubstanciar uma ação formativa realmente problematizadora, é necessário romper com os “... esquemas verticalizados...”. (Freire, 1987, p. 68). Esta é uma situação embaraçadora na EFA Cocais, visto ser a escola possuidora de um modelo pedagógico que lhe permite trabalhar o protagonismo e empoderamento dos estudantes a partir das situações concretas da vida dos mesmos, o que, porém visibiliza postura contrária no cotidiano da efetivação da ação formativa. 
A fala de Terra desperta a reflexão sobre os estudantes como meros seguidores de etapas que vão se desenhando paulatinamente no tempo escola e na sessão familiar. Este é um fator que pode contribuir para a ruptura no ciclo do $\mathrm{PE}$, a ausência do retorno para a comunidade das problematizações realizadas pelo PE.

Este ciclo do PE fundamentalmente se caracteriza pela: escolha dos temas geradores (Plano de Formação); mobilização dos estudantes; sensibilização temática (pode ser um momento de problematização); construção do $\mathrm{PE}$ (construção das questões); retorno para sessão familiar (campo de pesquisa do PE); retorno tempo escola; socialização das respostas (colocação em comum); retorno para comunidade (intervenção dos estudantes/professores/famílias).

$\mathrm{O}$ ciclo do PE aproxima das discussões de Berbel e Colombo (2007) ao criar uma metodologia da problematização que as autoras dispõem da seguinte forma: Observação da Realidade; Pontos-Chave; Teorização; Hipóteses de Solução e Aplicação à Realidade (prática). Na EFA Cocais, o estudo mostrou que existe a disponibilidade e a realização das etapas do PE, os estudantes e professores inclusive cumprem com todas as etapas citadas, deixando, contudo, de realizar a etapa da intervenção na comunidade a fim de transformar a realidade problematizada, o que eles denominam de atividade retorno do PE.

Claro que existem algumas iniciativas pontuais que, na perspectiva da gestão da escola, representam a ampliação da discussão do PE, mas funcionando dentro do ambiente escolar. Com relação à última etapa da metodologia da problematização, a ação de intervenção, segundo Villardi, Cyrino e Berbel (2015, p. 48),

... pois as decisões tomadas deverão ser executadas ou encaminhadas. Nesse momento, o componente social e político está mais presente. A prática que corresponde a esta etapa implica num compromisso dos alunos com o seu meio. Do meio observaram os problemas e para o meio levarão uma resposta de seus estudos, visando transformá-lo em algum grau.

Para as autoras, a metodologia da problematização deve seguir as etapas de forma a se constituir em sua integralidade, sem deixar lacunas para que ocorram processos concretos de mudanças significativas. Com relação ao PE na EFA Cocais e sua articulação com o viés da problematização na ação educativa, o estudo mostrou que o PE em seu viés problematizador acontece, no entanto deixando lacuna em sua trajetória, o que prejudica $\mathrm{o}$ andamento do comprometimento com as efetivas 
intervenções na realidade. $\mathrm{O}$ participante

Netuno coloca como um dos objetivos da

EFA em seus processos educativos que potencialize o jovem para ser “... formador de opiniões...”. (Netuno/entrevista). Além de articulador de opiniões, a escola defende a ação educativa que proporcione o protagonismo dos jovens como sujeitos históricos críticos.

Com relação à intervenção na comunidade e das possíveis soluções levantadas através da socialização e problematização realizadas em torno do tema do PE, Marte coloca que de cinco (05) PEs realizados na sessão com o terceiro ano, somente dois apresentaram ação interventiva na comunidade. Em relação ao uso de agrotóxico, Marte relata:

... uma visita a família...conjunta, pegaram os meninos da mesma localidade, "vamos fazer uma manhã..." na Chapada da Sindá, levaram para o campo e tudo, e expuseram a questão... foi exposta a questão do uso de agrotóxico, onde que a escola entrou né...então hoje, nem todos...Nãofoi cem por cento para comunidade, mas pelo menos os pais dos alunos que estudam aqui, eles tiveram...tiveram e tem uma visão diferente, hoje em dia na questão do uso, desse uso de agrotóxico, que foi tema do PE, já foram...isso aconteceu antes, mas depois veio o tema do PE. (Marte/entrevista).

A fala de Marte vislumbra a amplitude da dimensão problematizadora na ação formativa na EFA fomentada e produzida não somente pelo $\mathrm{PE}$, mas também pelas outras mediações. A intervenção que se deu com relação aos cuidados com o uso do agrotóxico foi possibilitada pela mediação pedagógica Visita às Famílias, mediação pedagógica que coloca os sujeitos que dinamizam a ação pedagógica no tempo escola, em contato com as famílias dos estudantes. Este momento para Marte significou uma realização profissional no sentido de perceber o quão importante é o contato com a realidade dos estudantes no meio sócio profissional onde a concretude da vida das famílias acontece entre lutas, conquistas diárias.

Ainda que a experiência com a temática dos agrotóxicos tenha comovido Marte, o mesmo reconhece que não existe uma intervenção da forma realmente expressiva, considerável conforme deveria ocorrer com o PE. Contudo, reconhece que é muito difícil realizar de fato essa dimensão do PE sendo a quantidade de municípios atendidos pela EFA Cocais ampla, em total de treze (13).

Com relação ao elemento conceitual da problematização, a interação nas falas dos sujeitos leva a crer que existe um direcionamento comum sobre a compreensão do termo, de forma unânime colocaram como uma questão que leva à 
discussão e que precisa ser solucionada,

conforme apresentadas no Quadro 1.

Quadro 1 - Fala dos participantes acerca do conceito da problematização.

\begin{tabular}{|c|c|}
\hline Mercúrio & $\begin{array}{l}\text { Um problema, uma situação que a gente busca uma resposta... Tentar buscar e ver se } \\
\text { aquilo que você está discutindo... Aquela sua inquietação ela tem algum objetivo, algum } \\
\text { resultado... }\end{array}$ \\
\hline Marte & É um problema exposto, aberto que a gente tenta trabalhar de alguma forma. \\
\hline Júpiter & ...é um assunto que envolve opiniões. \\
\hline Vênus & $\begin{array}{l}\text { Uma problematização que tem que ser resolvida... Ver a deficiência do lugar, corrigir o } \\
\text { solo para que todas as safras que forem plantadas tenham uma boa colheita... }\end{array}$ \\
\hline Saturno & ... eu não sei.... \\
\hline Urano & É um problema... alguma coisa assim, que tem que ser resolvida. \\
\hline Terra & $\begin{array}{l}\text { A gente encontra uma questão que deve ser discutida, e a gente pensa numa solução, } \\
\text { uma maneira para resolver. }\end{array}$ \\
\hline Netuno & $\begin{array}{l}\text { Está relacionado a problema, ...é aquilo que acontece e eu preciso ter capacidade de } \\
\text { superar. }\end{array}$ \\
\hline Plutão & $\begin{array}{l}\text {...tem um conjunto de pessoas, né, que se surgir algum problema ali... tem que aparecer } \\
\text { algo pra resolver aquela problematização." }\end{array}$ \\
\hline
\end{tabular}

Fonte: Arquivo pessoal da pesquisadora (2018).

A fala dos sujeitos interage com relativa harmonia, demonstrando alguns posicionamentos marcadamente individualizados na solução das questões problematizadas. As expressões dos participantes na pesquisa revelam a crença de que se existe um problema, existe também uma solução. A questão relativa ao aspecto da coletividade colocada por alguns dos participantes é condizente com a perspectiva da ação formativa na EFA Cocais, sendo que todas as atividades são realizadas fomentando a participação coletiva.

Em contato direto com EFA Cocais, como campo de pesquisa onde o objeto do presente estudo se materializou através das entrevistas etnográficas, as vozes dos participantes externaram a trajetória de construção do PE, em conformidade com o entendimento e a compreensão de cada um dos participantes que se mantém em contato com essa mediação no dia a dia da EFA que, de uma forma ou de outra, com maior intensidade ou não, existindo o contato com o PE de maneira mais próxima ou distanciada. O fato é que o estudo apontou que essa aproximação existe, bem como a produção de sentido que cada um constrói, todavia, necessitando de alguns elementos para as lacunas deixadas na trajetória de realização do PE em sua intencionalidade problematizadora, a fim de efetivar 
mudanças no contexto da realidade sócio profissional onde residem os jovens.

Mercúrio como motivador da construção do PE até sua socialização através da Colocação em Comum, apresenta um sentido dessa mediação pedagógica que, segundo afirma, é diferente de todos os outros professores, o PE “... é bem importante... é um dos temas que acho mais importante e delicado, o mais interessante de se trabalhar é o PE, né..." (Mercúrio/entrevista). A ênfase atribuída ao PE por Mercúrio pode estar relacionada coma identificação pessoal e profissional com essa mediação pedagógica em anos anteriores em outras EFAs. Outra possibilidade que remete a predileção de Mercúrio pelo PE, é o vínculo com a Pedagogia da Alternância nos primeiros momentos de formação inicial no Piauí. Formação promovida pela União Nacional das Escolas Família Agrícola no Brasil - UNEFAB em conjunto com Associação Regional das
Escolas Família Agrícola do Piauí AEFAPI antes de chegar à EFA Cocais. Esta fala de Mercúrio revela uma compreensão de formação na EFA, centrada na dinamização das mediações pedagógicas. Em seu entendimento, potencializar as mediações pedagógicas em sua realização concreta, em particular intensificando o PE como mediação principal é efetivar o que regem os princípios da Pedagogia da Alternância, inserção da realidade na ação educativa dos jovens para motivar mudanças sociais.

O envolvimento de Mercúrio é tão significativo, que está sempre atento na Colocação em Comum dos estudantes, estimulando e problematizando acerca dos elementos pontuados no PE. A Figura 1apresenta o encerramento dos PEs, no final do ano letivo de 2018, com os estudantes do terceiro ano em agropecuária, sessão de inserção da pesquisadora.

Figura 1 - Encerramento das Atividades de PE com estudantes do terceiro ano de Agropecuária.
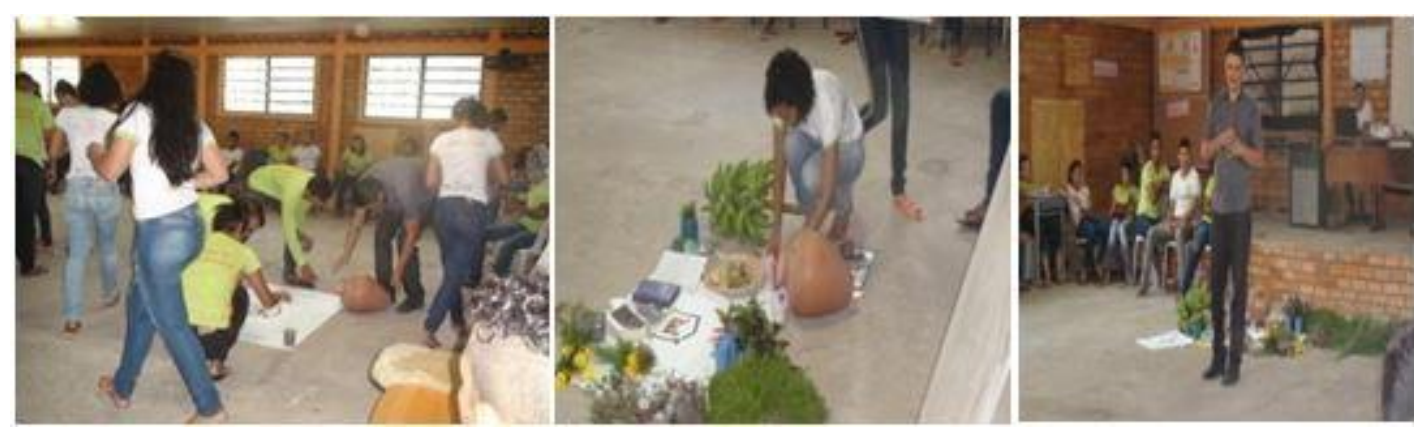

Fonte: Arquivo pessoal da pesquisadora (2018). 
No começo da manhã, logo após o café, todos os estudantes se dirigem para o auditório da escola a fim de realizarem um último encontro para encerramento das atividades do PE na EFA Cocais. Todos são convidados a produzir um painel que represente a EFA Cocais. O grupo se envolveu com a dinâmica sob o comando dos professores presentes. Com o prosseguimento da atividade que durou toda a manhã, foram chegando outros professores e membros da Associação dos Pais. Este momento significou muito para a pesquisa, pois se apresentaram distintas posturas e cenários no ambiente: estudantes que interagiam entre si, o envolvimento de um único sujeito com a condução da dinâmica e a postura passiva da maioria dos professores presentes. Os professores preferiam sempre deixar que o diretor conduzisse da melhor forma possível os trabalhos naquela manhã.

A proposta foi a seguinte: Em uma palavra dizer o que significou a EFA em sua vida nestes anos. As respostas foram simples, porém relevantes. Algumas bem reservadas e outras que geraram boas gargalhadas da turma. Não cabe ao estudo aqui apresentar todas as respostas, isso poderia incorrer em um desvio de foco do objeto pesquisado. Assim, de forma sintética as falas dos educandos diante da questão suscitada pelo gestor, foram: a
EFA em minha vida representou conhecimento/família/amizade/superação/a prendizagem/ companheirismo/ compromisso. Essas palavras expressam agradecimentos dos educandos pela existência da escola na região, bem como a especificidade da ação educativa da EFA.

Ao longo da construção deste tópico procurou-se costurar uma colcha de retalhos no sentido figurado, desde conceitos de problematizações até as formas como as falas se encontram e desencontram no contexto da EFA Cocais. As colocações de todos os participantes sobre o PE são relevantes, os sentidos atribuídos a esta mediação pedagógica expressam posicionamentos ora convergentes, ora divergentes, demonstrando a diversidade na unidade que Gimonet (2007) defende em se tratando da realização da Pedagogia da Alternância em sua expansão pelo mundo.

\section{Considerações finais}

Neste estudo percebe-se, tanto na entrevista como na observação participante, que os sujeitos envolvidos com a ação educativa na EFA Cocais, de modo geral, se envolvem com a dinamicidade do PE em sua efetividade cotidiana, mesmo que, conforme pontuamos ao longo do texto, este envolvimento não se configure de forma 
comprometida com os encaminhamentos e diretrizes que os pressupostos teóricos apontam e o próprio movimento do qual a EFA Cocais é parte, o CEFFAs.

Com essa constatação, o estudo mostrou o PE enquanto dimensão articuladora da realidade das famílias, através de eixos temáticos que condizem com a situação cotidiana dessas famílias, em sua realidade sócio, política, cultural e econômica. A dinamicidade do PE obedece a um fio condutor temático, que inicia com a origem da família e da comunidade, seguindo para o viés direcionado para a área produtiva, focando no desenvolvimento e empreendedorismo rural.

$\mathrm{O}$ fio condutor que direciona as questões que constituem o PE e que suscitam aos estudantes o ato de pesquisar é imbuído de intencionalidade problematizadora. Ao entrar em contato direto com a realidade que vivenciam através das questões que são construídas pelos próprios jovens, em conformidade com o eixo temático do $\mathrm{PE}$, esses estudantes iniciam um processo de exercício do olhar crítico e problematizador do cotidiano no que tange à reflexão sobre determinadas circunstâncias experienciadas em suas famílias e comunidades. Percebe-se, entretanto, na tessitura cotidiana da EFA, a naturalização do fortalecimento hegemônico do modelo de formação organizado no Plano de Formação. O discurso da ação formativa realizado pelos sujeitos que efetivam o trabalho educativo na EFA encontra-se voltado para a disseminação ideológica de que o modelo da alternância é a melhor alternativa para formação dos jovens que ainda estão no campo. É uma fala consensual da escola, tornar a Pedagogia da Alternância um caminho acertado para realizar a inserção das problemáticas da realidade das famílias no ambiente escolar, a fim de proporcionar uma ação educativa protagonizada.

O PE, em sua condição propositiva formativa, consegue ser o elemento relevante de aproximação reflexiva dos estudantes com suas vivências cotidianas, desafios, lutas, saberes culturais camponeses, políticas públicas direcionadas ao campo. Estes representam elementos cujo PE facilita o olhar problematizador dos estudantes através das questões que são colocadas para pesquisa na sessão familiar, faltando, contudo, superar lacunas na devolutiva à comunidade através da atividade retorno.

Outro aspecto importante é o envolvimento das outras dimensões, conforme mostrou o estudo. O caráter problematizador não se restringe ao $\mathrm{PE}$, mas é uma condição das outras mediações 
pedagógicas da alternância, tendo em vista que é no conjunto de todas elas, com a especificidade de cada uma que há motivação durante os processos educativos, que a formação vai acontecendo.

Este é um dos pontos que constatamos ser desafiador para EFA Cocais, pois o foco para o PE, as atenções que são colocadas em torno dessa mediação, representam na maioria das vezes, no cotidiano da escola, um esgotamento vivaz das outras mediações. Na escola, o PE é uma mediação que possui status hierárquico entre estudantes, professores e gestão. Este fato nos levou a constatar existir um apego ao PE que pode se configurar como uma busca da escola em justificar a formação em alternância exclusivamente pela realização das questões através do Plano de Estudo, que termina por se configurar com a efetivação da inserção da realidade das famílias no ambiente escolar.

O PE, através das questões que são construídas pelos estudantes referenciadas pelos eixos temáticos presentes no Plano de Formação, documento mestre para a organização do trabalho educativo na EFA Cocais, apresenta potencial para realizar processos formativos pautados pela realidade dos jovens em seu meio sócio profissional. A observação participante possibilitou constatar que os educandos são protagonistas no processo de construção das questões do PE, seguindo a dinamicidade organizacional da escola, que dispõe de professores para acompanhar esse processo, havendo por parte destes professores uma facilitação dos eixos temáticos a ser trabalhados pelos estudantes a fim de preparem o PE.

Como desafio a pesquisa evidenciou a superação da lacuna presente na realização do PE como mediação pedagógica que se dispõe a articular tempo/espaços e saberes distintos imbricados entre si. O ciclo do PE, iniciado com a seleção dos eixos temáticos que constituirão as questões a serem construídas e levadas para a sessão familiar pelos estudantes, é efetivado, mesmo com algumas fragilidades próprias do processo de educação que envolve os sujeitos e suas complexidades inerentes.

A lacuna encontra-se justamente na materialização da reflexão ocasionada pelo PE acerca da realidade das famílias e comunidades. Sua trajetória problematizadora esbarra, porém, na ausência de retorno para a comunidade com as possíveis soluções ou encaminhamentos que deveriam ocorrer por parte dos educandos com o auxílio dos professores, como forma de corporificar os resultados do PE debatidos e 
problematizados na Colocação em Comum, mediação responsável diretamente pela socialização das respostas sistematizadas pelos estudantes na sessão familiar.

Esta falta de retorno à comunidade, além de esgotar as possibilidades de possíveis mudanças das situações desafiadoras do cotidiano das famílias e da comunidade, nos campos produtivos, social, político econômico, termina também por limitar a dimensão problematizadora do Plano de Estudo, imprimindo-lhe o aspecto estéril, e incumbindo-lhe de caráter burocrático a ser cumprido pelos estudantes com vistas a adquirir nota qualitativa ao final de cada sessão.

A falta da atividade retorno incorre na quebra do ciclo processual do PE como mediação pedagógica de caráter interdisciplinar. Constata-se que essa mediação possui índole problematizadora da realidade dos estudantes; o PE consegue inserir nos processos formativos, mesmo que não estabeleça relações interdisciplinares com a maioria das disciplinas, as discussões sobre a realidade dos estudantes em seu meio sócio profissional.

A falta da atividade retorno perspectivada pelo $\mathrm{PE}$, e das possíveis intervenções realizadas pelos estudantes e professores no meio sócio profissional desses estudantes, incide na dificuldade de potencializar o protagonismo dos estudantes com a transformação de suas realidades. Esse pode ser um aspecto que possivelmente encontra-se fundamentado na ausência da participação efetiva e significativa dos estudantes na construção do Plano de Formação, documento que rege os processos formativos na escola e que pauta as temáticas da realidade a serem trabalhadas no PE.

A questão da participação na construção do Plano de Formação, momento de seleção das temáticas que compõem o PE, desvelou-se através da observação participante, no dia a dia da EFA, contando somente com os professores e alguns membros da associação de pais quando convidados. Os estudantes terminam por aguardar os encaminhamentos e as diretrizes com relação ao PE, bem como as outras mediações que serão executadas no cotidiano da escola. Um dos exercícios na ação educativa na EFA Cocais que motivaria processos de formação efetivamente pautados no aspecto da postura transformadora da realidade, através do protagonismo dos estudantes, seria o envolvimento efetivo dos mesmos nos momentos iniciais de seleção dos eixos temáticos a serem desenvolvidos através 
do PE. Talvez através deste envolvimento dos estudantes desde a trajetória inicial do PE, ou seja, a seleção dos eixos temáticos baseados na realidade das famílias, os educandos assumam a condição de protagonistas provocando mudanças em seus contextos sócio profissionais, políticos, culturais e econômicos.

Assinala-se também que, no cotidiano da EFA Cocais, no fazer pedagógico, na realização das mediações pedagógicas, mesmo enfrentando ainda alguns desafios, como, por exemplo, o envolvimento significativo dos professores e mesmo de alguns estudantes, a alternância segue em sua dinamicidade. $\mathrm{O}$ PE, como parte de um conjunto de mediações pedagógicas, demonstrou, na presente pesquisa, a sua dimensão problematizadora na medida em que facilita a articulação entre a realidade vivenciada nas/pelas famílias e a ação formativa no ambiente escolar.

Contudo, o PE, bem como as outras mediações, deixa margens para perspectivas de outros estudos, no sentido de significar esse modelo de formação. A Pedagogia da Alternância ainda se configurar com relativo desconhecimento no campo dos estudos científicos educacionais. As mediações pedagógicas da alternância tornam-se um meio para que os saberes constituídos fora do espaço escolar ganhem relevância na ação formativa exercida no interior do ambiente escolar. Esta é praticamente o que diferencia a modalidade da alternância da modalidade regular de ensino em nível de Estado.

\section{Referências}

André, M. E. D. A. (1995). Etnografia na prática escolar. Campinas, SP: Papirus.

André, M. E. D. A. (1984). Estudo de caso: seu potencial na educação. Cad. Pesq., (49), 51-54. Recuperado de: http://publicacoes.fcc.org.br/ojs/index.php/ cp/article/view/1427/1425

Angrosino, M. (2009). Etnografia $e$ observação participante. Tradução de José Fonseca. Porto Alegre: Artmed.

Bakhtin, M. (2006). Marxismo e filosofia da linguagem. $12 . \quad$ ed. São Paulo:HUCITEC

Brait, B. (Org.). (2005). Bakhtin: dialogismo e construção do sentido. 2. ed. rev. Campinas, SP: Ed. UNICAMP.

Colombo, A. A., \& Berbel, N. A. N. (2007). A Metodologia da Problematização com o Arco de Maguerez e sua relação com os saberes de professores. Semina: Ciências Sociais e Humanas, 28(2), 121$146 . \quad$ Recuperado de: http://www.sgc.goias.gov.br/upload/links/a rq_390_ametodologiadaproblematizacaoco moarcodemaguerez.pdf

Fairclough, N. (2008). Discurso $e$ mudança social. Brasília: Editora Universidade de Brasília.

Freire, P. (1987). Pedagogia do oprimido. 17. ed. Rio de Janeiro: Paz e Terra. 
Gimonet, C. J. (2007). Praticar $e$ compreender a pedagogia da alternância dos CEFFAs. Tradução de Thierry Burghgrave. Petrópolis, RJ: Vozes; Paris: AIMFR - Associação Internacional dos Movimentos familiares de Formação Rural.

Jesus, J. G. (2011). Formação de professores na pedagogia da alternância. Vitória, ES: GM.

Mészáros, I. (2005). A educação para além do capital. Tradução de Isa Tavares. São Paulo: Boitempo.

Villardi, M. L., Cyrino, E. G., \& Berbel, N. A. N. (2015). A metodologia da problematização no ensino em saúde: suas etapas e possibilidades. In $A$ problematização em educação em saúde: percepções dos professores tutores e alunos [online] (pp. 45-52). São Paulo: Editora UNESP; São Paulo: Cultura Acadêmica. Recuperado de: http://books.scielo.org/id/dgjm7/pdf/villard i-9788579836626-05.pdf

\section{Informações do artigo / Article Information}

Recebido em : 31/07/2019

Aprovado em: 30/09/2019

Publicado em: 19/12/2019

Received on July 31th, 2019

Accepted on September 30th, 2019

Published on December, 19th, 2019

Contribuições no artigo: As autoras foram as responsáveis por todas as etapas e resultados da pesquisa, a saber: elaboração, análise e interpretação dos dados; escrita e revisão do conteúdo do manuscrito e; aprovação da versão final publicada.

Author Contributions: The author were responsible for the designing, delineating, analyzing and interpreting the data, production of the manuscript, critical revision of the content and approval of the final version published.

Conflitos de interesse: As autoras declararam não haver nenhum conflito de interesse referente a este artigo.

Conflict of Interest: None reported.

Orcid

Maria Raquel Barros Lima

iD https://orcid.org/0000-0003-0614-4454

Carmen Lúcia de Oliveira Cabral

(iD) https://orcid.org/0000-0001-9916-0466

Como citar este artigo / How to cite this article

APA

Lima, M. R. B., \& Cabral, C. L. O. (2019). Plano de Estudo $(\mathrm{PE})$ da Pedagogia da Alternância: perspectiva problematizadora na ação formativa da Escola Família Agrícola dos Cocais/PI (EFA Cocais/PI). Rev. Bras. Educ. Camp., $4, \quad$ e7322. DOI: http://dx.doi.org/10.20873/uft.rbec.e7322

ABNT

LIMA, M. R. B.; CABRAL, C. L. O. Plano de Estudo (PE) da Pedagogia da Alternância: perspectiva problematizadora na ação formativa da Escola Família Agrícola dos Cocais/PI (EFA Cocais/PI). Rev. Bras. Educ. Camp., Tocantinópolis, v. 4, e7322, 2019. DOI: http://dx.doi.org/10.20873/uft.rbec.e7322 